\title{
Effects of time-lagged meteorological variables on attributable risk of leishmaniasis in central region of Afghanistan
}

\author{
Majeed A. Adegboye ${ }^{\mathrm{a}}$, Jamiu Olumoh ${ }^{\mathrm{b}}$, Timor Saffary ${ }^{\mathrm{c}}$, Faiz Elfaki ${ }^{\mathrm{d}, 1}$, Oyelola A. Adegboye ${ }^{\mathrm{e}, \mathrm{f}, *, 1}$ \\ a American University of Nigeria, 640001 Yola, Nigeria \\ ${ }^{\mathrm{b}}$ Department of Mathematics, American University of Nigeria, 640001 Yola, Nigeria \\ ${ }^{\mathrm{c}}$ Independent researcher, $\mathrm{MD}$, United States \\ d Department of Mathematics, Statistics and Physics, Qatar University, 2713 Doha, Qatar \\ e Department for Management of Science and Technology Development, Ton Duc Thang University, Ho Chi Minh City, Viet Nam \\ f Faculty of Mathematics and Statistics, Ton Duc Thang University, Ho Chi Minh City, Viet Nam
}

\section{H I G H L I G H T S}

- This study presents the burden of leishmaniasis attributable to time-varying meteorological variables using DLNM.

- Temperature effects were immediate and persistent, and highest at cold temperatures.

- Disparity of risk was observed in subgroup analysis.

- Extreme cold temperatures exerted increased risk of leishmaniasis for males and younger people (aged $<60$ years).

- Elderly people were the most sensitive to high temperature.

\section{G R A P H I C A L A B S T R A C T}

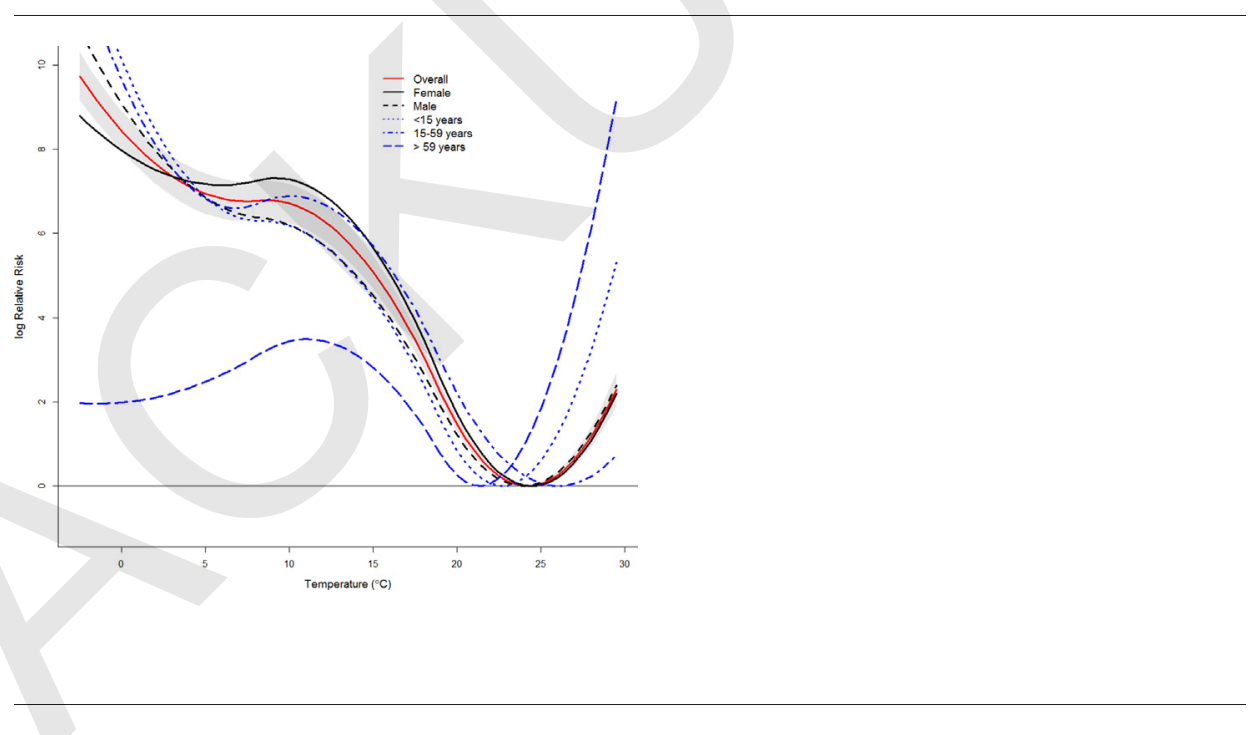

A B S T R A C T

Background: Leishmaniasis remains one of the world's most neglected vector-borne diseases, affecting predominantly poor communities mainly in developing countries. Previous studies have shown that the distribution and dynamics of leishmaniasis infections are sensitive to environmental factors, however, there are no studies on the burden of leishmaniasis attributable to time-varying meteorological variables.

Methods: This study used data from 3 major leishmaniosis afflicted provinces of Afghanistan, between 2003 and 2009, to provide empirical analysis of change in heat/cold-leishmaniosis association. Non-linear and delayed exposure-lag-response relationship between meteorological variables and leishmaniasis were fitted with a distributed lag non-linear model applying a spline function which describes the dependency along the range of values with a lag of up to 12 months. We estimated the risk of leishmaniasis attributable to high and low temperature.

Results: The median monthly mean temperature and rainfall were $16.1^{\circ} \mathrm{C}$ and $0.6 \mathrm{in}$., respectively. Seasonal variations of leishmaniasis were consistent between males and females, however significant differences were observed among different age groups. Temperature effects were immediate and persistent (lag 0-12 months).

\footnotetext{
* Corresponding author at: Ton Duc Thang University, Ho Chi Minh City, Viet Nam.

E-mail address: oyelola.adegboye@tdtu.edu.vn (O.A. Adegboye).

1 Senior authors.
} 
The cumulative risks were highest at cold temperatures. The cumulative relative risks (logRR) for leishmaniasis were 6.16 (95\% CI: 5.74-6.58) and 1.15 (95\% CI: $1.32-1.31)$ associated with the 10th percentile temperature $\left(2.16{ }^{\circ} \mathrm{C}\right)$ and the 90 th percentile temperature $\left(28.46^{\circ} \mathrm{C}\right)$. The subgroup analysis showed increased risk for males as well as young and middle aged people at cold temperatures, however, higher risk was observed for the elderly in heat. The overall leishmaniasis-temperature attributable fractions was estimated to be $7.6 \%$ (95\% CI: $7.5 \%-7.7 \%$ ) and mostly due to cold.

Conclusion: Findings in this study highlight the non-linearity, delay of effects and magnitude of leishmaniasis risk associated with temperature. The disparity of risk between different subgroups can hopefully advise policy makers and assist in leishmaniasis control program.

(C) 2019 The Author(s). Published by Elsevier B.V. This is an open access article under the CC BY-NC-ND license (http://creativecommons.org/licenses/by-nc-nd/4.0/).

\section{Introduction}

Leishmaniasis is still one of the world's most neglected vector-borne diseases, largely affecting poor communities (Kassi et al., 2008; Leslie et al., 2006; Mubayi et al., 2010) in developing countries (Bailey et al., 2017). Approximately, 350 million people are at risk of contracting leishmaniasis, and some 2 million new cases occur every year (Gradoni et al., 2017; World Health Organization, 2010). Leshmaniasis infection causes significant health burdens and can have negative social and psychological stigma which could lead to significant economic losses (Adegboye and Kotze, 2012; Bern et al., 2008; Kassi et al., 2008). Leishmaniasis is a parasitic disease caused by Leishmania parasite, which is transmitted to human and animal hosts by the bite of phlebotomine sandflies (Erguler et al., 2019; Leslie et al., 2006). The geographical distribution of leishmaniasis is tied in to the abundance of sandflies, their life cycle, and the presence of reservoirs (Erguler et al., 2019; Koch et al., 2017; Mubayi et al., 2010).

Clinical manifestations of can cause Visceral Leishmaniasis (VL), also called Kala-azar which is the most serious form of the disease; Cutaneous Leishmaniasis (CL), which is the most common; and MucoCutaneous Leishmaniasis (MCL) or Diffuse-Cutaneous Leishmaniasis (DCL), which rarely occurs (Adegboye and Adegboye, 2017; Bates, 2007; Casolari et al., 2005; Mubayi et al., 2010; Salah et al., 2007). The coexistence of these clinical forms in the same patient is very rare (Gradoni et al., 2017). VL is potentially fatal (Leslie et al., 2006; Ready, 2014), with a case fatality rate of about $10 \%$. Jaundice, wasting severe anaemia, and HIV co-infection are associated with increased risk of VL lethality (Assunção et al., 2001; Bern et al., 2008) while malaria coinfection increases the risk of $\mathrm{CL}$ in the endemic region (Adegboye and Adegboye, 2017).

Based on global estimates, approximately 200,000 to $400,000 \mathrm{VL}$ cases and 700,000 to 1.2 million CL cases occur each year (Alvar et al., 2012; Gradoni et al., 2017). Approximately, 90\% of global VL cases occur in just six countries: India, Bangladesh, Sudan, South Sudan, Brazil and Ethiopia (Alvar et al., 2012). Similarly, ten countries account for $70 \%$ to $75 \%$ of estimated global CL incidences (Afghanistan, Algeria, Colombia, Brazil, Iran, Syria, Ethiopia, North Sudan, Costa Rica and Peru) (Alvar et al., 2012; Bern et al., 2008) with Afghanistan having approximately $90 \%$ of these infections (Bern et al., 2008; Kassi et al., 2008).

Afghanistan has been plagued by leishmaniasis since the ninth century when it was called the "Balkh Sore" named after the Afghan province north of the capital Kabul (Hepburn, 2003; Reyburn et al., 2003; Stewart and Brieger, 2009). The disease continued to expand with number of infections growing across Afghanistan as endemics became more prevalent (Ashford et al., 1992; Omar et al., 1969; Stewart and Brieger, 2009). The occurrence of leishmaniasis in Afghanistan varies widely from year to year, showing an upward trend and repeating patterns related to the months of the years, thereby indicating of nonstationarity and nonlinearity characteristics (Adegboye and Adegboye, 2017; Faulde et al., 2008). Previous studies have suggested that Leishmania parasite is sensitive to climatic variables such as temperature, rainfall, relative humidity, and wind speed which could be used to explain the increasing occurrence of the parasite in the region (Galgamuwa et al.,
2018; Koch et al., 2017). The strong association observed between leishmaniasis and meteorological change is supported by the environmental factors associated with the distribution of $\mathrm{CL}$ in West Afghanistan. These include the Harirud River, farm irrigation, Haplocalcids with Torriorthents and Torrifluvents soils types and an elevation range of 700-1200 m, which provides suitable humidity and temperatures to support the breeding and ensure the survival of the sandflies (Adegboye and Adegboye, 2017; Erguler et al., 2019; Fakhar et al., 2017; Koch et al., 2017).

The close association of Leshmaniasis distribution with climate and meteorological conditions may be used to predict Leshmaniasis epidemics in Afghanistan (Adegboye and Adegboye, 2017; Elnaiem et al., 2003; Galgamuwa et al., 2018; Plourde et al., 2012). However, there is no study on the burden of leishmaniasis attributable to time-varying meteorological variables to inform a more understanding of the endemic disease. This study is aimed to fill this gap by investigating the meteorological variables-leishmaniasis association among vulnerable groups and assess the health burden of leishmaniasis attributable to meteorological variables in Central Afghanistan.

\section{Methods}

\subsection{Study area and leishmaniasis data}

Leshmaniasis is endemic in Afghanistan. The data used in this study were retrospective records of clinically-diagnosed leishmaniasis cases in Afghanistan between 2003 and 2009 obtained from the Afghanistan Health Management Information System (HMIS) under the National Malaria and leishmaniasis Control Programme (NMLCP) of the Ministry of Public Health (MoPH). Three neighbouring provinces (Kabul, Kapisa and Logar) in the central region with high incidence of leishmaniasis were considered in this study (Fig. 1). Kabul is regarded as having the highest incidence of CL in the world, with an estimated share of 33.75\% cases annually (Faulde et al., 2008; Jebran et al., 2014; Reithinger and Coleman, 2007; Reithinger et al., 2010). Monthly counts of leishmaniasis were disaggregated by age groups $[<15$ years, 15-59 years and 60+ years] and gender.

\subsection{Meteorological data}

The meteorological variables used in this study were mean land surface temperature (LST) and rainfall. Satellite-derived environmentalLST was obtained from the Moderate Resolution Imaging Spectroradiometer (MOD11 L2 version 6, USGS/Earth Resources Observation and Science (EROS) Center, Sioux Falls, South Dakota) at $1 \mathrm{~km}$ spatial resolution while the monthly accumulated rainfall data measured by the Tropical Rainfall Measuring Mission (TRMM: TMPA/ 3B43) jointly conducted by NASA and the Japan Aerospace Exploration Agency (JAXA). The extraction techniques of these meteorological variables have been discussed elsewhere (Adegboye et al., 2018). In summary, the extracted satellite images were processed in DIVA-GIS (Hijmans et al., 2012) and R geospatial packages (Bivand et al., 2013) 


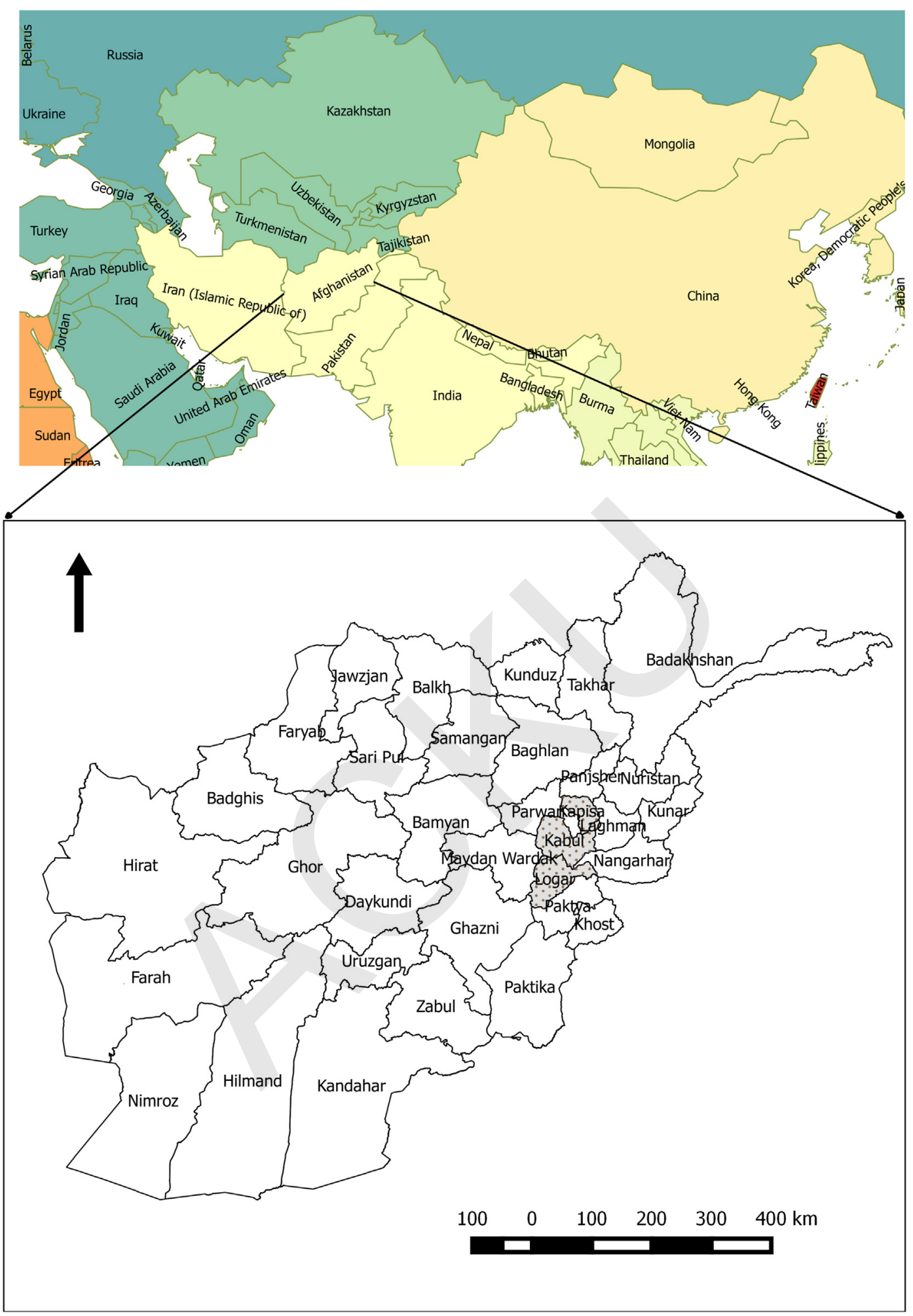

Fig. 1. Map of Afghanistan showing the study region (Kapisa, Kabul and Logar province).

and re-projected to the georeferenced spatial frame to facilitate the extraction of the image pixel values.

\subsection{Statistical analysis}

\subsubsection{Descriptive analysis}

First a preliminary analysis of monthly leishmaniasis cases was carried out followed by a visualization of the seasonal patterns of climatic variables in relation to leishmaniasis from 2003 to 2009. A two-way analysis of variance was performed to assess the contribution of between monthly variability to the total variability while seasonal Mann-Kendall trend test was applied to detect leishmaniasis monthly trends over the study period. Additionally, chi-square test was used to test if a variation in monthly leishmaniasis cases between males and females, and across different age groups ( $<15$ years, $15-59$ years and 60 + years) existed. 


\subsubsection{Meteorological variables-leishmaniasis associations}

To assess the effect of climatic variables, we used a distributed lag non-linear model (DLNM) (Gasparrini et al., 2010; Gasparrini, 2011, 2014; Gasparrini et al., 2017) with random intercept (Wu et al., 2017) to modelled counts of leishmaniasis $\left(Y_{i t}\right)$ at month $t$ in province $i$ via Poisson regression adjusting for population, seasonality, long-term trend with meteorological variables - temperature $\left({ }^{\circ} \mathrm{C}\right)$ and rainfall (in.),

$$
\begin{gathered}
Y_{i t} \sim \operatorname{Poisson}\left(\mu_{i t}\right) \\
\log \left(\mu_{i t}\right)=\alpha_{0 i}+\log \left(\text { Population }_{i t}\right)+\sum_{l=0}^{12} s\left(x_{i t-l} \beta_{l}\right)+\sum_{j=1}^{J} f_{j}\left(u_{i t, j} \gamma_{j}\right) \\
\alpha_{0 i} \sim N\left(\alpha_{0}, \sigma^{2}{ }_{0}\right)
\end{gathered}
$$

where $\alpha_{0 i}$ is a random intercept to capture provincial level dependencies, $\alpha_{0}$ overall average intercept and $\sigma^{2}{ }_{0}$ is the province-level variability around $\alpha_{0}$; Population $_{i t}$ represents the population of province $i$ at month $t$; The function, $f_{j}$ is used to specify the functional relationship between variables $u_{i t j}$ and the nonlinear exposure-response curve, defined by the parameter vectors $\gamma_{j}$. Natural cubic spline with 3 degrees of freedom was used to define smooth function, $f_{j 1}\left(u_{i t, 1} \gamma_{j}\right)$ for rainfall.

The function, $s\left(x_{i t-l} \beta_{l}\right)$ described the dependency along the range of exposure values and lag dimension (up to 12 months). Thus, we modelled the non-linear and delayed exposure-lag-response relationship between the temperature and leishmaniasis with a spline function. The cross-basis parameterization for the exposure-lag-response is given by:

$s(x, t)=\int_{l_{0}=0}^{12} f \cdot w\left(x_{t-l}, l\right) d l \approx \sum_{l_{0=0}}^{12} f \cdot w\left(x_{t-l}, l\right)=w_{x, t}^{T} \eta$

The bi-dimensional function $f \cdot w\left(x_{t-l}, l\right)$ represents the exposurelag-response function, and model simultaneously the exposureresponse $f(x)$ curve along temperature range and lag-response curve, $\omega(l)$ (Gasparrini, 2014).

The predictions for the cumulative exposure-lag-response association derived from the parameter estimates from the Poisson regression model (1) for varying meteorological values and lags were then displayed as exposure-lag-response curve of relative risk.

\subsubsection{Attributable risk measure}

The attributable fraction, which is an indicator of exposure-related health burden, was calculated by using the effect summaries from the DLNM models and treating the associations with exposures at different lags as independent contributions to the risk (Gasparrini and Leone, 2014). We defined the optimum exposure as the value of meteorological variable at which leishmaniasis risk is the lowest in the estimated exposure-response curve. With the optimum exposure value as reference, for each lag of the series, in a province, we used the overall cumulative relative risk corresponding to each lag's exposure to calculate the

\section{Table 2}

Summary of weather variables, temperature, wind and counts of leishmaniasis in the study region.

\begin{tabular}{lrrrrrrr}
\hline Variables & Mean & SD & Min & \multicolumn{2}{c}{ Percentile } & \multirow{2}{*}{ Max } \\
\cline { 5 - 6 } & & & & 25 & \multicolumn{1}{c}{50} & \multicolumn{1}{c}{75} & \\
\hline Leishmaniasis & 270.4 & 419.6 & 0 & 0 & 145.0 & 288.5 & 3047.0 \\
Mean temperature $\left({ }^{\circ} \mathrm{C}\right)$ & 15.4 & 9.4 & -2.5 & 7.1 & 16.1 & 25.0 & 29.6 \\
Rainfall (in.) & 1.3 & 2.8 & 0 & 0.2 & 0.6 & 2.0 & 9.7 \\
\hline
\end{tabular}

attributable number and fraction of attributable number in the next $l$ lags.

\subsubsection{Model selection and model assessment}

To capture the flexibility of the exposure-lag-response relationship, $f$ $\cdot w\left(x_{t-l}, l\right)$, we explored constant, linear and quadratic B-splines for the temperature-lag-leishmaniasis functional relationship with a lag of up to 12 months. Additionally, we explored different choices for the lag number (3, 6, 9 and 12), the number of knots and position as well as the dfs for seasonality and long-term trends (2-8) and rainfall (2-8). The models were assessed with Akaike Information Criteria (AIC). All analyses were done using the package dlnm (Gasparrini, 2011) in R 3.4.2 statistical software ( $R$ Core Team, 2017). The empirical confidence intervals (eCls) were obtained via Monte Carlo simulations.

\section{Results}

\subsection{Summary of disease and meteorological variables}

A total 67,942 cases of leishmaniasis were reported in the study region between 2003 and 2009. The baseline characteristics of infection are presented in Table 1. Kabul province accounted for $67.2 \%$ of the total cases, primarily in middle aged (15-59 years) population. The median monthly mean temperature was $16.1{ }^{\circ} \mathrm{C}$ with an interquartile range between $7.1{ }^{\circ} \mathrm{C}$ and $25.0^{\circ} \mathrm{C}$. The median monthly rainfall was 0.6 in. (Table 2). Fig. 2 displays the distributions of monthly leishmaniasis cases by age and gender. The disease occurrence is characterized by repeated ups and downs generally with two peaks-March/April and July (Fig. 2a). The seasonal Mann-Kendall trend test of the equality of monthly occurrence was rejected $(p<0.001)$. Similarly, seasonal variations of leishmaniasis were consistent between males and females, however, significant differences were observed among different age groups (Fig. 2b-c).

\subsection{Meteorological-leishmaniasis association}

The relative risks (RRs) from the best fitted DLNM model described by a quadratic B-splines for temperature-leishmaniasis relationship, linear function for lag-leishmaniasis, a natural cubic splines for rainfall with 6 degrees of freedom (dfs) to capture seasonality and long-term trend were presented in Fig. 3 and Table 3. The 3-D plot shows that the temperature-leishmaniasis association was nonlinear, immediate

Table 1

\begin{tabular}{|c|c|c|c|c|c|}
\hline \multirow[t]{2}{*}{ Characteristics } & \multicolumn{5}{|l|}{$\mathrm{N}\left(\%^{\mathrm{a}}\right)$} \\
\hline & Total & p-Value & Kabul & Kapisa & Logar \\
\hline Overall & $67,942(100 \%)$ & & $45,631(67.2 \%)$ & $10,546(15.5 \%)$ & $11,765(17.3 \%)$ \\
\hline Male & $31,598(46.5)$ & 0.278 & $20,627(45.2)$ & $5308(50.3)$ & $5663(47.3)$ \\
\hline Female & $36,344(53.5)$ & & $25,004(54.8)$ & $5238(49.7)$ & $6102(52.7)$ \\
\hline \multicolumn{6}{|l|}{ Age group } \\
\hline$<15$ years & $11,999(17.7)$ & $<0.001$ & $9763(21.4)$ & $1011(9.6)$ & $1225(10.2)$ \\
\hline $15-59$ years & $31,004(45.6)$ & & $22,399(49.1)$ & 4140 (39.3) & 4465 (37.3) \\
\hline$>59$ years & 24,939 (36.7) & & $13,469(29.5)$ & 5395 (51.2) & 6075 (50.7) \\
\hline
\end{tabular}

Summary characteristics of leishmaniasis in three provinces during the study period, 2003-2009.

a Percentage of the total cases, 67,942. 
and persisted throughout the 12 month lag period. The effect was significantly higher at low temperatures and maximum at lag 0. Fig. 3 and Table 3 show the overall effect, log Relative Risk (logRR) of temperature on the risk of leishmaniasis for up to 12 months lag and at specific lags and temperature values. The result indicates that the disease was associated with temperature, was highest at lag 0 and declined over the entire lag periods but remained significant. The increased risk of leishmaniasis during the cold temperature was highest at moderate cold temperature. For example, at $2.16{ }^{\circ} \mathrm{C}$ the cumulative risk (logRR) was 6.16 (95\% CI: 5.74-6.58).

The leishmaniasis-temperature curve revealed (not shown) different optimum temperatures for the subgroup analysis, ranging from $21.4{ }^{\circ} \mathrm{C}$ for the elderly group ( $>59$ years) to $26.0^{\circ} \mathrm{C}$ for the middle age group (15-59 years). Similarly, the magnitude of the association between temperature and incidence of leishmaniasis varied slightly among different subgroups (Table 3). A general increased risk of leishmaniasis during extreme cold and extreme heat among different subgroups was discovered. The increased risk of leishmaniasis during the cold period was higher for males than females at temperatures lower than $5{ }^{\circ} \mathrm{C}$. However, the temperature-leishmaniasis effect was protective during the heat period at lower lags but increased at longer lags (Table 3). There was an increased risk of cold weather among young and middle age people. In contrast, the cumulative risk for heat (6.99, 95\% CI: 6.40-7.58) was higher for the elderly (60+ years) than for cold (1.97, 95\% CI: 1.19-2.74).

\subsection{Attributable risk of leishmaniasis}

Table 4 presents the leishmaniasis fraction (\%) attributable to nonoptimum temperatures for the entire group as well as its subgroups. The attributable fractions (AF) of the disease are much higher for cold temperatures, especially for moderate cold temperatures (temperatures below the optimum temperature but above 2.5 th percentile). The overall estimated $\mathrm{AF}$ was $7.6 \%$ (95\% CI: 7.5\%-7.7\%) and mostly due to cold. In the sub-group analysis, the total AF was lowest due to temperature in elderly people (3.7\%, $95 \% \mathrm{CI}: 1.4 \%-5.0 \%)$ while the younger age group had the highest AF (7.5\%, 95\% CI: 7.1\%-7.7\%). Generally, most of leishmaniasis-temperature $\mathrm{AF}$ can be attributed to moderate temperatures except in case of the older group (2.5\%, 95\% CI: $2.3 \%-2.9 \%)$.

\section{Discussion}

Several previous studies have shed light on the role of environmental factors such as temperature, rainfall and altitude on Leishmaniasis and vector, sandflies (Adegboye et al., 2017; Bhunia et al., 2010; Cardenas et al., 2006; Ford et al., 2016; Kassem et al., 2012; Lewnard et al., 2014; Toumi et al., 2012). In fact, recently introduced forecasting models heavily depend on weather and climate data as predictors, an approach which has led to higher precision over longer time periods (Chaves and Pascual, 2006; Erguler et al., 2019; Lewnard et al., 2014; Talmoudi et al., 2017). Because of this dependency on environmental factors, global warming is expected to continue shifting the geographical distribution of sandflies and leishmaniasis northward with the first phlebotomine sandflies already being sighted in previously leishmaniasis-free regions such as Germany and Belgium (Chalghaf et al., 2018). One previous study focuses on other risk factors for Anthropological CL (ACL) in Kabul at the household level including things such as sex, age, number of household, household construction materials, etc. (Reithinger et al., 2010).

Previous studies revealed that temperature had a significant effect on the development and spread of leishmaniasis (Adegboye and Adegboye, 2017; Chalghaf et al., 2018; Hlavacova et al., 2013). In the present study, we examined the delay and nonlinear impact of temperature on clinically-diagnosed cases of leishmaniasis in three major affected Afghan provinces, Kabul, Kapisa and Logar, between 2003 and 2009, with Kabul having the highest CL cases world-wide. The almost four-decade long civil war in Afghanistan has increased the number of leishmaniasis cases significantly to an estimated 67,000 annual cases nationwide (Reithinger et al., 2003). Unlike most previous studies, this study applied distributed lag nonlinear model with random effect to capture the spatial proximity of the three provinces.

Whereas temperature and rainfall were the environmental variables, temperature was the main dependable variable in this study. Following a first visualization of seasonal patterns, Mann-Kendall trend and chi-square tests were conducted to analyze the monthly trends and potential differences between monthly Leishmaniasis cases of different subgroups. The impact of climatic factors on leishmaniasis was analyzed with a distributed lag non-linear model and Poisson regression. The exposure-lag-relationship was examined with constant, linear

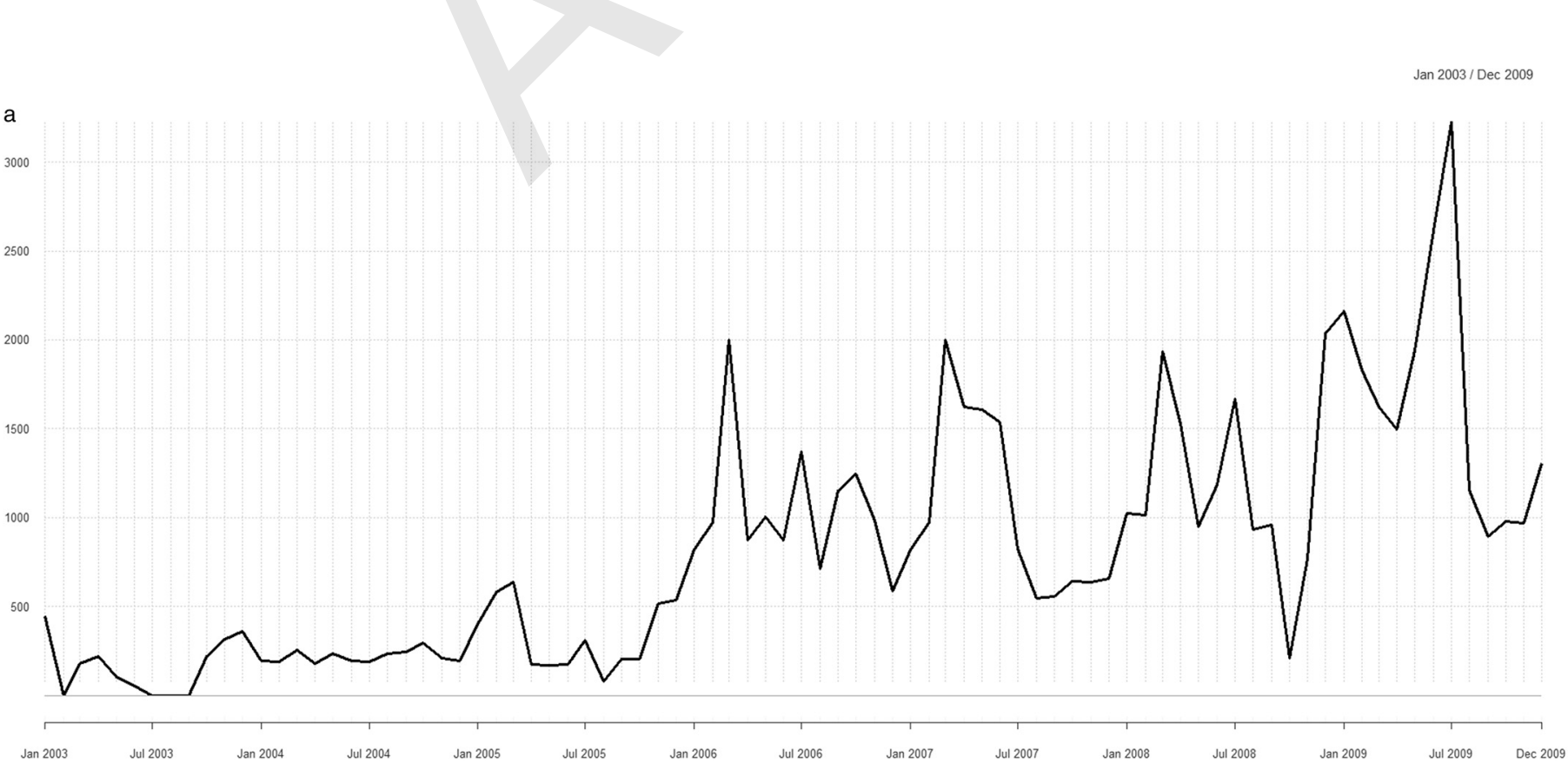

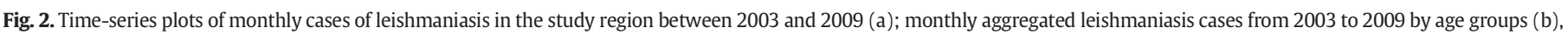
gender (c). 
b

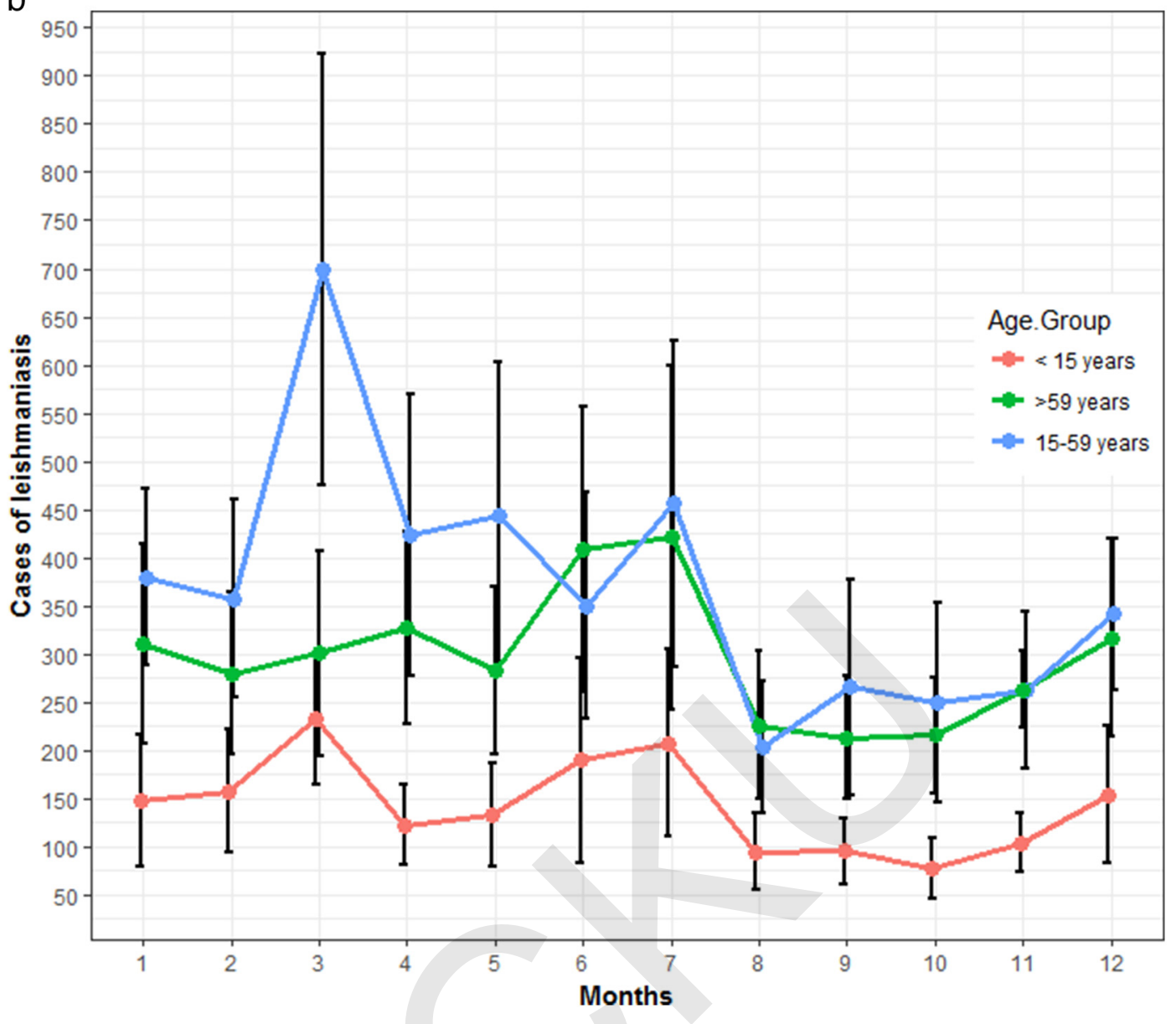

Fig. 2 (continued).

and quadratic B-splines for the temperature-lag-leishmaniasis relationship. Our study findings and key implications are summarized below.

The first outcome of this study is that the impact of temperature on leishmaniasis is observed immediately and could persist throughout the entire year, indicating a crucial temperature dependency of the sandfly. Thus, the aforementioned studies were correct to incorporate climate dependencies in their models for forecasting leishmaniasis. The relatively high accuracy of twelve-month CL prediction of $72 \%-77 \%$, which is significantly higher than models with no climate predictors, justifies this approach as well (Chaves and Pascual, 2006). Our results showed an increased risk of leishmaniasis during cold temperature (highest at moderate temperature) which confirms the endophagic character of the sandfly in Afghanistan (Reithinger et al., 2010). During this period individuals are mostly indoors, a reason why the rate of infection was at its peak. This result is in agreement with the sandfly vector dynamics since leishmaniasis cases in Afghanistan are predominantly ACL cases. ACL transmission starts in November with an incubation period of 4-6 weeks, climb to a peak in February-March and fall through August with almost no cases from September to November (Faulde et al., 2008). In the cold period people spend more time inside the house, thus higher vector exposure is expected between dusk and dawn which may result in increased sandfly bites (Killick-Kendrick et al., 1995). Factors like poor sanitation, bad housing conditions and bad nets gave access to sandflies thereby providing breeding grounds and increasing the risk of infection (Okwor and Uzonna, 2016). A case study between the Old World (L. longipalpis, P. perniciosus) and New World (L. braziliensis, L. peruviana) species reveals the impact of ambient temperature on leishmaniasis vector's life cycle exposing the different species to a temperature at $20^{\circ} \mathrm{C}$ and $26^{\circ} \mathrm{C}$ (Hlavacova et al., 2013). The experiment revealed that at an early stage of infection the species thrived at $26{ }^{\circ} \mathrm{C}$ and started to defecate at days 8-9 losing almost all of its infection. In comparison, lower temperatures $\left(20{ }^{\circ} \mathrm{C}\right)$ delayed its defecation explaining a higher spread of the infection at $20^{\circ} \mathrm{C}$ and not $26^{\circ} \mathrm{C}$.

The leishmaniasis-temperature association in this study has different optimums for the subgroups, with relative risk being lowest for the older subgroup (above 59 years) at $21.4^{\circ} \mathrm{C}$ and highest for the younger group (between 15 and 59 years) at $26.0^{\circ} \mathrm{C}$. Our results also show that the relative risk during the cold period was higher for males than females which is consistent with previous findings (Reithinger et al., 2003). This could be explained by behavioral patterns of Afghans defined by religion, tradition and low living standards. All ages and both genders are susceptible to leishmaniasis, especially those in regular contact with sandflies (Leta et al., 2014), however, the strict dress code for Muslim women, which requires covering most of the skin, could explain the lower vector exposure for women and higher vector exposure for men. The subgroup analysis showed that the risk during cold periods was higher for the age group younger than 60 years in accordance with previous studies (Reithinger et al., 2010). Similarly, matured male migrant agricultural/field workers as well as displaced women and children are highly exposed to sandflies and at higher risk of leishmaniasis (Leta et al., 2014).

Finally, in addition to the parasite favourable ecological and environmental parameters in parts of Afghanistan, other factors such as armed conflict, movement of large parts of the population, destructed infrastructure, very low living standards, and an insufficient health-care system have contributed to the fast spread of the disease (Desjeux, 2001; 


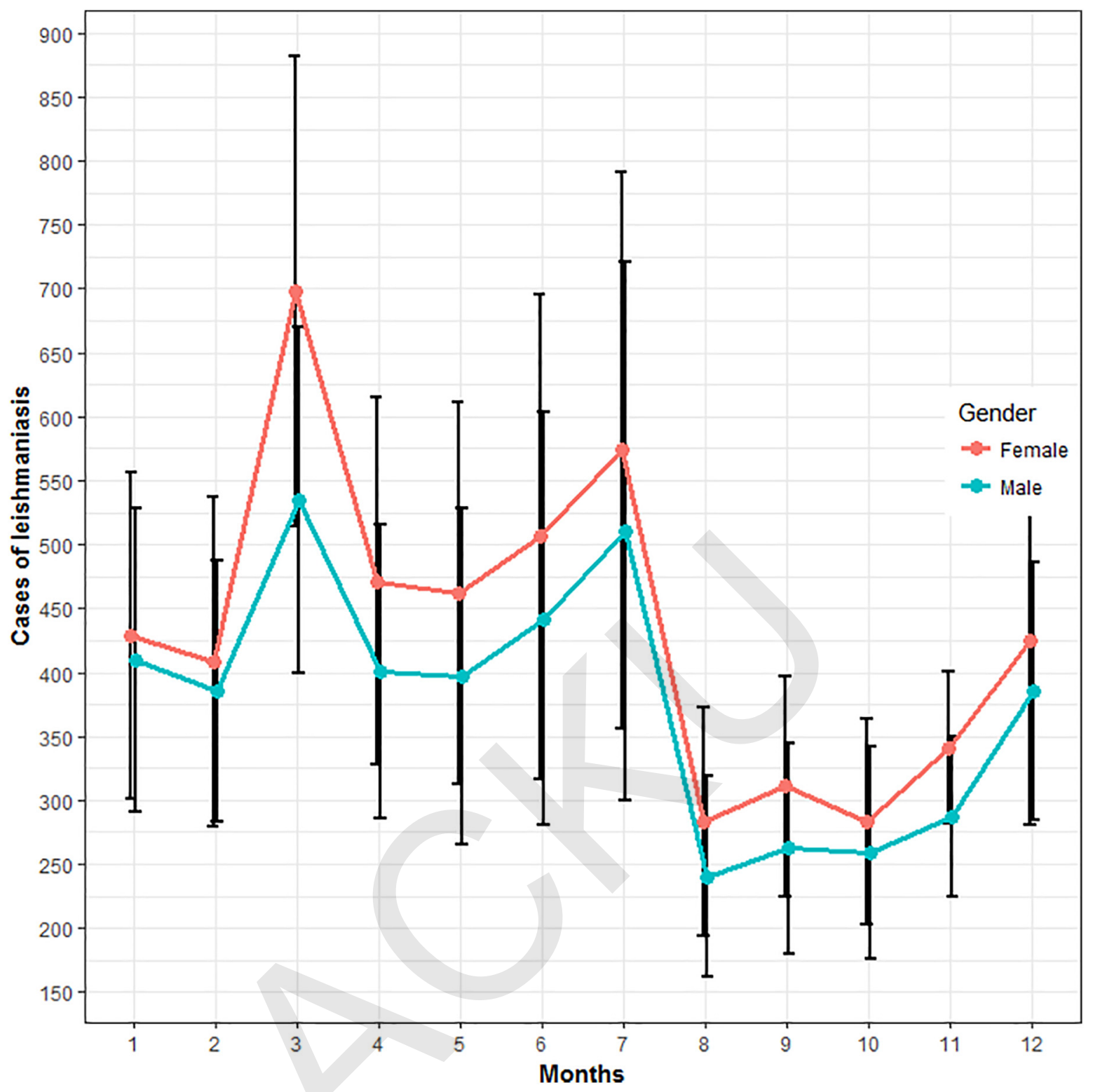

Fig. 2 (continued).

Nadim and Rostami, 1974; Reithinger et al., 2003). The latest epidemic has been mainly caused by the almost four-decade long armed conflict with all of its disastrous implications. The war has led to millions of casualties and an exodus of millions of Afghans and internally displaced populations (Refugee Studies Centre, 2014). The markedly increasing trend of leishmaniasis during these periods can be attributed to increased population around the capital, Kabul. Repatriation of millions of returning Afghans, most of whom could not return to their origins due to ongoing conflicts and economic constraints, were forced to settle down in and around main cities (Refugee Studies Centre, 2014). According to a prevalence study in Kabul City in 2001, 2.7\% persons have leishmaniasis lesion and 21.9\% have leishmaniasis scars (Reithinger et al., 2003). Kabul has been prone to the disease since it has been suffering from a population explosion in addition to low living standards, poor infrastructure and healthcare services.

The first major limitation of this study is that the meteorological variables used were not measured at the individual level. Secondly, there are potentially other leishmaniasis mediating risk factors other than temperature and rainfall, whose inclusion could possibly affect the overall effect sizes extent and interpretation. Thirdly, the aggregated leishmaniasis surveillance data used in this study did not clearly distinguish between ACL and Zoonotic CL (ZCL) cases. Lastly, the smooth functions used to capture the exposure-lag-response relationships are difficult to validate in DLNM (Gasparrini et al., 2017). Nevertheless, the assumptions made in this study are reasonable in the absence of adequate information. This study presents an important addition to prior knowledge of leishmaniasis-temperature association in Afghanistan.

\section{Conclusions}

This study on documented leishmaniasis cases in three Afghan provinces has confirmed the importance of environmental and climatic factors for the spread of the disease, in particular its dependency on temperature. The differentiation between different subgroups of affected people led to a deeper insight into the infection process and could contribute to new and more precise forecasting models as well as assist in formulating new preventive initiatives. 


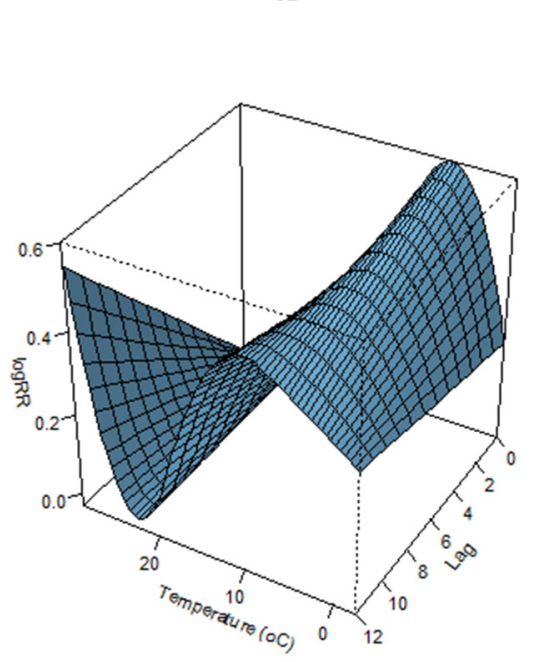

Overall

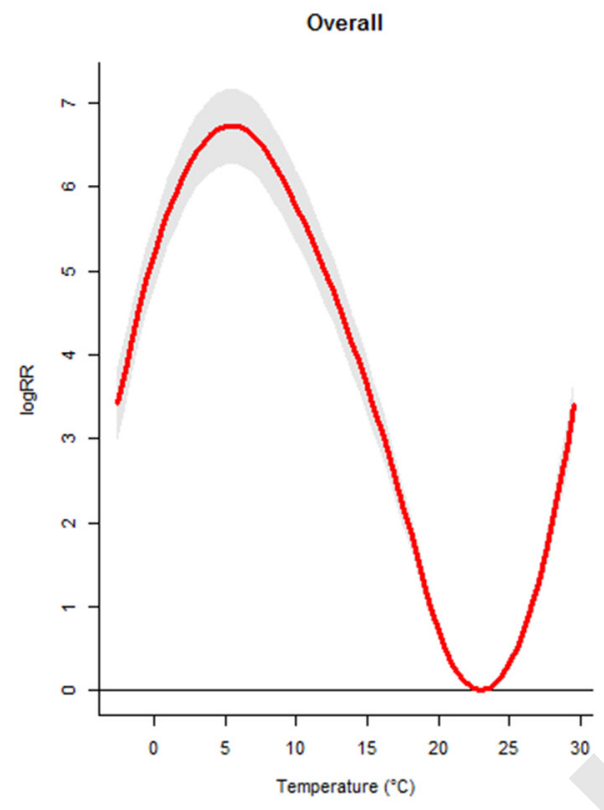

Lag-specific effects at $\left(5^{\circ} \mathrm{C}\right)$

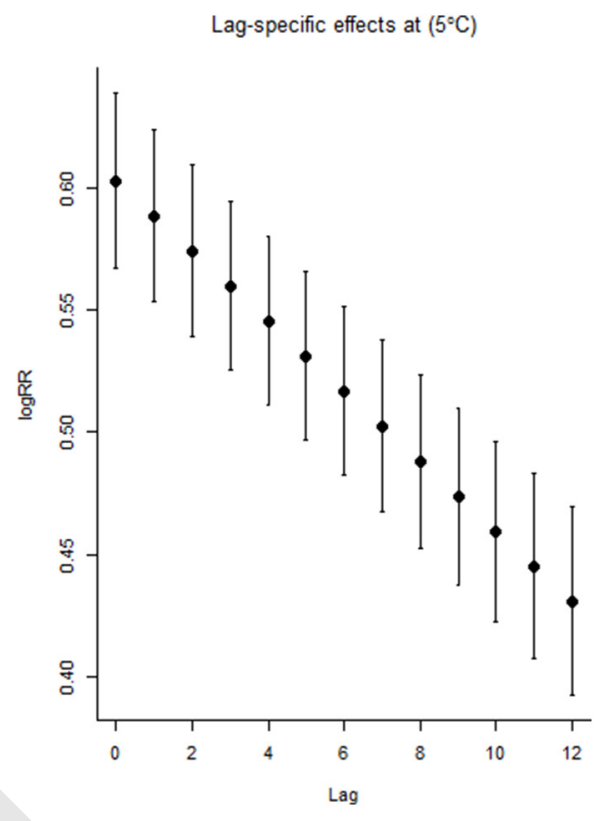

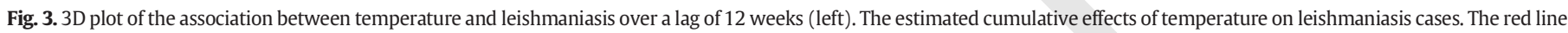
represents the estimated logRR from DLNM model and the shaded area indicates its $95 \%$ confidence interval (middle). Lag-specific association at $5{ }^{\circ} \mathrm{C}$ (right).

Table 3

Association (logRR) between leishmaniasis and temperature at specific exposure-lag in different subgroups.

\begin{tabular}{|c|c|c|c|c|c|c|c|}
\hline \multirow[t]{2}{*}{ Subgroup } & \multirow[t]{2}{*}{ Temperature } & \multicolumn{6}{|l|}{$\log \mathrm{RR}(95 \% \mathrm{CI})$} \\
\hline & & Lag 0 & Lag 3 & Lag 6 & Lag 9 & Lag12 & Lag 0-12 \\
\hline \multirow[t]{4}{*}{ Overall } & 2.5 th $\left(-0.35^{\circ} \mathrm{C}\right)$ & $0.41(0.38-0.45)$ & $0.40(0.37-0.42)$ & $0.38(0.35-0.41)$ & $0.37(0.33-0.40)$ & $0.35(0.31-0.39)$ & $4.97(4.57-5.37)$ \\
\hline & 10 th $\left(2.16^{\circ} \mathrm{C}\right)$ & $0.55(0.53-0.59)$ & $0.52(0.48-0.55)$ & $0.47(0.44-0.50)$ & $0.43(0.39-0.47)$ & $0.39(0.35-0.43)$ & $6.16(5.74-6.58)$ \\
\hline & 90 th $\left(26.78^{\circ} \mathrm{C}\right)$ & $-0.03(-0.04$ to -0.01$)$ & $0.03(0.02-0.04)$ & $0.09(0.08-0.10)$ & $0.15(0.13-0.16)$ & $0.21(0.19-0.22)$ & $1.15(1.32-1.31)$ \\
\hline & 97.5th $\left(28.46^{\circ} \mathrm{C}\right)$ & $-0.03(-0.06$ to -0.01$)$ & $0.08(0.06-0.10)$ & $0.18(0.16-0.21)$ & $0.29(0.27-0.32)$ & $0.40(0.27-0.43)$ & $2.40(2.67-2.67)$ \\
\hline \multicolumn{8}{|l|}{ Gender } \\
\hline \multirow[t]{4}{*}{ Male } & 2.5 th $\left(-0.35^{\circ} \mathrm{C}\right)$ & $0.70(0.64-0.76)$ & $0.71(0.65-0.76)$ & $0.71(0.66-0.77)$ & $0.72(0.66-0.78)$ & $0.73(0.67-0.79)$ & $9.29(8.60-9.99)$ \\
\hline & 10 th $\left(2.16^{\circ} \mathrm{C}\right)$ & $0.57(0.52-0.63)$ & $0.59(0.54-0.64)$ & $0.61(0.55-0.66)$ & $0.62(0.56-0.68)$ & $0.63(0.58-0.69)$ & $7.89(7.21-8.57)$ \\
\hline & 90 th $\left(26.78{ }^{\circ} \mathrm{C}\right)$ & $-0.05(-0.08$ to -0.04$)$ & $-0.01(-0.03-0.01)$ & $0.04(0.03-0.07)$ & $0.10(0.08-0.12)$ & $0.15(0.13-0.18)$ & $0.62(0.39-0.84)$ \\
\hline & 97.5 th $\left(28.46^{\circ} \mathrm{C}\right)$ & $-0.08(-0.12$ to -0.04$)$ & $0.02(-0.01-0.05)$ & $0.12(0.09-0.15)$ & $0.22(0.18-0.26)$ & $0.32(0.27-0.27)$ & $1.58(1.15-2.01)$ \\
\hline \multirow[t]{4}{*}{ Female } & 2.5 th $\left(-0.35^{\circ} \mathrm{C}\right)$ & $0.51(0.45-0.57)$ & $0.56(0.52-0.61)$ & $0.62(0.56-0.67)$ & $0.67(0.62-0.73)$ & $0.73(0.66-0.78)$ & $8.06(7.40-8.72)$ \\
\hline & 10 th $\left(2.16^{\circ} \mathrm{C}\right)$ & $0.54(0.49-0.59)$ & $0.56(0.51-0.61)$ & $0.57(0.53-0.63)$ & $0.59(0.54-0.65)$ & $0.61(0.56-0.67)$ & $7.48(6.84-8.13)$ \\
\hline & 90th $\left(26.78^{\circ} \mathrm{C}\right)$ & $-0.06(-0.07$ to -0.04$)$ & $-0.01(-0.03-0.00)$ & $0.04(0.02-0.05)$ & $0.08(0.07-0.10)$ & $0.13(0.11-0.15)$ & $0.46(0.28-0.65)$ \\
\hline & 97.5 th $\left(28.46^{\circ} \mathrm{C}\right)$ & $-0.09(-0.12$ to -0.05$)$ & $0.01(-0.02-0.04)$ & $0.11(0.08-0.14)$ & $0.20(0.17-0.24)$ & $0.30(0.26-0.35)$ & $1.38(1.01-1.76)$ \\
\hline \multicolumn{8}{|c|}{ Age (years) } \\
\hline \multirow[t]{4}{*}{$<15$} & $2.5 \operatorname{th}\left(-0.35^{\circ} \mathrm{C}\right)$ & $0.82(0.71-0.92)$ & $0.81(0.71-0.91)$ & $0.80(0.71-0.89)$ & $0.80(0.71-0.89)$ & $0.79(0.69-0.89)$ & $10.45(9.26-11.64)$ \\
\hline & 10th $\left(2.16^{\circ} \mathrm{C}\right)$ & $0.59(0.51-0.68)$ & $0.62(0.53-0.71)$ & $0.64(0.55-0.73)$ & $0.67(0.57-0.76)$ & $0.69(0.59-0.79)$ & $8.35(7.17-9.54)$ \\
\hline & 90 th $\left(26.78^{\circ} \mathrm{C}\right)$ & $-0.01(-0.05-0.04)$ & $0.07(0.03-0.11)$ & $0.15(0.10-0.19)$ & $0.22(0.11-0.27)$ & $0.30(0.24-0.36)$ & $1.91(1.36-2.45)$ \\
\hline & 97.5 th $\left(28.46{ }^{\circ} \mathrm{C}\right)$ & $0.02(-0.05-0.11)$ & $0.16(0.09-0.23)$ & $0.29(0.22-0.36)$ & $0.43(0.22-0.51)$ & $0.56(0.46-0.67)$ & $3.81(2.89-1.72)$ \\
\hline \multirow[t]{4}{*}{$15-59$} & 2.5 th $\left(-0.35^{\circ} \mathrm{C}\right)$ & $0.89(0.83-0.95)$ & $0.83(0.77-0.88)$ & $0.77(0.71-0.82)$ & $0.70(0.64-0.76)$ & $0.64(0.57-0.70)$ & $9.96(9.21-10.70)$ \\
\hline & 10th $\left(2.16^{\circ} \mathrm{C}\right)$ & $0.74(0.69-0.80)$ & $0.68(0.63-0.73)$ & $0.62(0.56-0.67)$ & $0.55(0.49-0.61)$ & $0.49(0.42-0.55)$ & $8.02(7.27-8.76)$ \\
\hline & 90 th $\left(26.78{ }^{\circ} \mathrm{C}\right)$ & $-0.03(-0.03$ to -0.02$)$ & $-0.01(-0.02$ to -0.01$)$ & $0.01(-0.01-0.01)$ & $0.02(0.01-0.02)$ & $0.03(0.02-0.04)$ & $0.03(-0.04-0.11)$ \\
\hline & 97.5 th $\left(28.46^{\circ} \mathrm{C}\right)$ & $-0.07(-0.10$ to -0.04$)$ & $-0.02(-0.05-0.00)$ & $0.03(0.01-0.05)$ & $0.08(0.05-0.11)$ & $0.13(0.09-0.16)$ & $0.35(0.05-0.66)$ \\
\hline \multirow[t]{4}{*}{$60+$} & 2.5 th $\left(-0.35^{\circ} \mathrm{C}\right)$ & $-0.24(-0.31$ to -0.17$)$ & $-0.04(-0.11-0.01)$ & $0.15(0.09-0.21)$ & $0.35(0.29-0.41)$ & $0.55(0.49-0.61)$ & $1.97(1.19-2.74)$ \\
\hline & 10th $\left(2.16^{\circ} \mathrm{C}\right)$ & $-0.14(-0.19$ to -0.08$)$ & $0.01(-0.04-0.07)$ & $0.16(0.11-0.22)$ & $0.32(0.26-0.37)$ & $0.47(0.40-0.53)$ & $2.11(1.39-2.83)$ \\
\hline & 90 th $\left(26.78^{\circ} \mathrm{C}\right)$ & $0.08(0.04-0.11)$ & $0.19(0.16-0.22)$ & $0.31(0.28-0.34)$ & $0.43(0.39-0.46)$ & $0.55(0.51-0.59)$ & $4.07(3.68-4.46)$ \\
\hline & 97.5 th $\left(28.46^{\circ} \mathrm{C}\right)$ & $0.17(0.11-0.23)$ & $0.36(0.31-0.40)$ & $0.54(0.49-0.58)$ & $0.72(0.67-0.77)$ & $0.90(0.84-0.97)$ & $6.99(6.40-7.58)$ \\
\hline
\end{tabular}

Table 4

Attributable fraction (\%) of leishmaniasis due to temperature together with their 95\% empirical confidence interval.

\begin{tabular}{|c|c|c|c|c|c|}
\hline & Total temperatures & Extreme cold ${ }^{\mathrm{a}}$ & Moderate cold $^{\mathrm{b}}$ & Moderate heat $^{\mathrm{b}}$ & Extreme heat $^{\mathrm{a}}$ \\
\hline Overall & $7.6(7.5-7.7)$ & $0.4(0.3-0.5)$ & $5.5(5.4-5.6)$ & $1.5(1.3-1.6)$ & $1.7(1.6-1.8)$ \\
\hline \multicolumn{6}{|l|}{ Gender } \\
\hline Male & $7.4(7.2-7.6)$ & $0.3(0.2-0.4)$ & $6.8(5.9-6.2)$ & $1.0(0.7-1.2)$ & $1.2(0.9-1.4)$ \\
\hline Female & $7.4(7.2-7.6)$ & $0.3(0.2-0.4)$ & $5.8(5.7-6.0)$ & $0.8(0.5-1.0)$ & $1.0(0.5-1.2)$ \\
\hline \multicolumn{6}{|c|}{ Age (years) } \\
\hline$<15$ & $7.5(7.1-7.7)$ & $0.4(0.2-0.5)$ & $5.2(4.7-5.6)$ & $1.7(1.5-1.9)$ & $1.9(1.7-2.1)$ \\
\hline $15-59$ & $6.3(5.6-7.0)$ & $0.3(0.3-0.5)$ & $6.2(6.1-6.3)$ & $-0.4(-0.9-0.1)$ & $-0.3(-1.1-0.3)$ \\
\hline $60+$ & $3.7(1.4-5.0)$ & $0.1(-0.1-0.3)$ & $1.2(-0.9-2.4)$ & $2.1(2.0-2.2)$ & $2.5(2.5-2.9)$ \\
\hline
\end{tabular}

a Extreme-cold and -heat are temperatures lower than the 2.5th percentile (extreme cold) and higher than the 97.5th percentile (extreme heat), respectively.

b Moderate cold are temperatures from 2.5th percentile to the optimum temperature, and moderate heat is temperatures from the optimum temperature to the 97.5 th percentile. 


\section{Declaration of Competing Interest}

All authors declare that there are no conflicts of interest.

\section{Acknowledgements}

Faiz Elfaki's research was supported by the Qatar University internal grant (GUST-1-CAS-2019-53).

\section{References}

Adegboye, O., Adegboye, M., 2017. Spatially correlated time series and ecological niche analysis of cutaneous leishmaniasis in Afghanistan. Int. J. Environ. Res. Public Health $14,309$.

Adegboye, O., Kotze, D., 2012. Disease mapping of leishmaniasis outbreak in Afghanistan spatial hierarchical bayesian analysis. Asian Pac. J. Trop. Dis. 2, 253-259.

Adegboye, O., Al-Saghir, M., Leung, D., 2017. Joint spatial time-series epidemiologica analysis of malaria and cutaneous leishmaniasis infection. Epidemiol. Infect. 145, 685-700.

Adegboye, O.A., Leung, D.H., Wang, Y.G., 2018. Analysis of spatial data with a nested correlation structure. J. R. Stat. Soc.: Ser. C: Appl. Stat. 67, 329-354.

Alvar, J., Vélez, I.D., Bern, C., Herrero, M., Desjeux, P., Cano, J., et al., 2012. Leishmaniasis worldwide and global estimates of its incidence. PLoS One 7, e35671.

Ashford, R., Kohestany, K., Karimzad, M., 1992. Cutaneous leishmaniasis in Kabul: observations on a 'prolonged epidemic'. Ann. Trop. Med. Parasitol. 86, 361-371.

Assunção, R.M., Reis, I.A., Oliveira, C.D.L., 2001. Diffusion and prediction of leishmaniasis in a large metropolitan area in Brazil with a bayesian space-time model. Stat. Med. 20, 2319-2335.

Bailey, F., Mondragon-Shem, K., Hotez, P., Ruiz-Postigo, J.A., Al-Salem, W., Acosta-Serrano, A., et al., 2017. A new perspective on cutaneous leishmaniasis-implications for global prevalence and burden of disease estimates. PLoS Negl. Trop. Dis. 11, e0005739.

Bates, P.A., 2007. Transmission of leishmania metacyclic promastigotes by phlebotomine sand flies. Int. J. Parasitol. 37, 1097-1106.

Bern, C., Maguire, J.H., Alvar, J., 2008. Complexities of assessing the disease burden attributable to leishmaniasis. PLoS Negl. Trop. Dis. 2, e313.

Bhunia, G.S., Kesari, S., Jeyaram, A., Kumar, V., Das, P., 2010. Influence of topography on the endemicity of kala-azar: a study based on remote sensing and geographical information system. Geospat. Health 4, 155-165.

Bivand, R., Keitt, T., Rowlingson, B., Pebesma, E., Sumner, M., Hijmans, R., 2013. Bindings for the geospatial data. Abstraction library r package version 08-14.

Cardenas, R., Sandoval, C.M., Rodriguez-Morales, A.J., Franco-Paredes, C., 2006. Impact of climate variability in the occurrence of leishmaniasis in northeastern Colombia. Am. J. Trop. Med. Hyg. 75, 273-277.

Casolari, C., Guaraldi, G., Pecorari, M., Tamassia, G., Cappi, C., Fabio, G., et al., 2005. A rare case of localized mucosal leishmaniasis due to leishmania infantum in an immunocompetent italian host. Eur. J. Epidemiol. 20, 559-561.

Chalghaf, B., Chemkhi, J., Mayala, B., Harrabi, M., Benie, G.B., Michael, E., et al., 2018. Ecological niche modeling predicting the potential distribution of leishmania vectors in the mediterranean basin: impact of climate change. Parasit. Vectors 11, 461.

Chaves, L.F., Pascual, M., 2006. Climate cycles and forecasts of cutaneous leishmaniasis, a nonstationary vector-borne disease. PLoS Med. 3, e295.

Desjeux, P., 2001. The increase in risk factors for leishmaniasis worldwide. Trans. R. Soc. Trop. Med. Hyg. 95, 239-243.

Elnaiem, D.-E.A., Schorscher, J., Bendall, A., Obsomer, V., Osman, M.E., Mekkawi, A.M., et al., 2003. Risk mapping of visceral leishmaniasis: the role of local variation in rainfall and altitude on the presence and incidence of kala-azar in eastern Sudan. Am. J. Trop. Med. Hyg. 68, 10-17.

Erguler, K., Pontiki, I., Zittis, G., Proestos, Y., Christodoulou, V., Tsirigotakis, N., et al., 2019. A climate-driven and field data-assimilated population dynamics model of sand flies. Sci. Rep. 9, 2469.

Fakhar, M., Karamian, M., Ghatee, M.A., Taylor, W.R., Pazoki Ghohe, H., Rasooli, S.A., 2017. Distribution pattern of anthroponotic cutaneous leishmaniasis caused by leishmania tropica in western Afghanistan during 2013-2014. Acta Trop. 176, 22-28.

Faulde, M., Schrader, J., Heyl, G., Amirih, M., 2008. Differences in transmission seasons as an epidemiological tool for characterization of anthroponotic and zoonotic cutaneous leishmaniasis in northern Afghanistan. Acta Trop. 105, 131-138.

Ford, E., Carroll, J.A., Smith, H.E., Scott, D., Cassell, J.A., 2016. Extracting information from the text of electronic medical records to improve case detection: a systematic review. J. Am. Med. Inform. Assoc. 23, 1007-1015.

Galgamuwa, L.S., Dharmaratne, S.D., Iddawela, D., 2018. Leishmaniasis in Sri Lanka: spatial distribution and seasonal variations from 2009 to 2016. Parasit. Vectors 11, 60 .

Gasparrini, A., 2011. Distributed lag linear and non-linear models in r: the package dlnm. J. Stat. Softw. 43, 1-20

Gasparrini, A., 2014. Modeling exposure-lag-response associations with distributed lag non-linear models. Stat. Med. 33, 881-899.

Gasparrini, A., Leone, M., 2014. Attributable risk from distributed lag models. BMC Med. Res. Methodol. 14, 55.

Gasparrini, A., Armstrong, B., Kenward, M.G., 2010. Distributed lag non-linear models. Stat. Med. 29, 2224-2234.
Gasparrini, A., Scheipl, F., Armstrong, B., Kenward, M., 2017. A penalized framework for distributed lag non-linear models. Biometrics 73, 938-948.

Gradoni, L., López-Vélez, R., Mokni, M., 2017. Manual on Case Management and Surveillance of the Leishmaniases in the Who European Region. World Health Organization Regional Office for Europe, Copenhagen.

Hepburn, N.C., 2003. Cutaneous leishmaniasis: an overview. J. Postgrad. Med. 49, 50.

Hijmans, R., Guarino, L., Mathur, P., 2012. Diva-gis. Version 7.5. A geographic information system for the analysis of species distribution data. Available at: www.diva-gis.org.

Hlavacova, J., Votypka, J., Volf, P., 2013. The effect of temperature on leishmania (kinetoplastida: Trypanosomatidae) development in sand flies. J. Med. Entomol. 50, 955-958.

Jebran, A.F., Schleicher, U., Steiner, R., Wentker, P., Mahfuz, F., Stahl, H.-C., et al., 2014. Rapid healing of cutaneous leishmaniasis by high-frequency electrocauterization and hydrogel wound care with or without dac n-055: a randomized controlled phase iia trial in Kabul. PLoS Negl. Trop. Dis. 8, e2694.

Kassem, H.A., Siri, J., Kamal, H.A., Wilson, M.L., 2012. Environmental factors underlying spatial patterns of sand flies (diptera: Psychodidae) associated with leishmaniasis in southern Sinai, Egypt. Acta Trop. 123, 8-15.

Kassi, M., Afghan, A.K., Rehman, R., Kasi, P.M., 2008. Marring leishmaniasis: the stigmatization and the impact of cutaneous leishmaniasis in Pakistan and Afghanistan. PLoS Negl. Trop. Dis. 2, e259.

Killick-Kendrick, R., Killick-Kendrick, M., Tang, Y., 1995. Anthroponotic cutaneous leishmaniasis in Kabul, Afghanistan: the high susceptibility of phlebotomus sergenti to leishmania tropica. Trans. R. Soc. Trop. Med. Hyg. 89, 477.

Koch, L.K., Kochmann, J., Klimpel, S., Cunze, S., 2017. Modeling the climatic suitability of leishmaniasis vector species in europe. Sci. Rep. 7, 13325

Leslie, T., Saleheen, S., Sami, M., Mayan, I., Mahboob, N., Fiekert, K., et al., 2006. Visceral leishmaniasis in Afghanistan. CMAJ 175, 245-246.

Leta, S., Dao, T.H.T., Mesele, F., Alemayehu, G., 2014. Visceral leishmaniasis in Ethiopia: an evolving disease. PLoS Negl. Trop. Dis. 8, e3131.

Lewnard, J.A., Jirmanus, L., Júnior, N.N., Machado, P.R., Glesby, M.J., Ko, A.I., et al., 2014. Forecasting temporal dynamics of cutaneous leishmaniasis in Northeast Brazil. PLoS Negl. Trop. Dis. 8, e3283.

Mubayi, A., Castillo-Chavez, C., Chowell, G., Kribs-Zaleta, C., Ali Siddiqui, N., Kumar, N., et al., 2010. Transmission dynamics and underreporting of kala-azar in the indian state of Bihar. J. Theor. Biol. 262, 177-185

Nadim, A., Rostami, G.S., 1974. Epidemiology of cutaneous leishmaniasis in Kabul, Afghanistan. Bull. World Health Organ. 51, 45.

Okwor, I., Uzonna, J., 2016. Social and economic burden of human leishmaniasis. Am. J. Trop. Med. Hyg. 94, 489-493.

Omar, A., Saboor, A., Amin, F., Sery, V., 1969. Preliminary study on the foci of cutaneous leishmaniasis in Kabul City. Z. Tropenmed. Parasitol. 20.

Plourde, M., Coelho, A., Keynan, Y., Larios, O.E., Ndao, M., Ruest, A., et al., 2012. Genetic polymorphisms and drug susceptibility in four isolates of leishmania tropica obtained from Canadian soldiers returning from Afghanistan. PLoS Negl. Trop. Dis. 6, e1463.

R Core Team, 2017. R: A Language and Environment for Statistical Computing. R Foundation for Statistical Computing, Vienna, Austria.

Ready, P.D., 2014. Epidemiology of visceral leishmaniasis. Clin. Epidemiol. 6, 147-154.

Refugee Studies Centre, 2014. Forced Migration Review No. 46-Afghanistan's Displaced People: 2014 and Beyond. vol. 46

Reithinger, R., Coleman, P.G., 2007. Treating cutaneous leishmaniasis patients in Kabul, Afghanistan: cost-effectiveness of an operational program in a complex emergency setting. BMC Infect. Dis. 7, 3.

Reithinger, R., Mohsen, M., Aadil, K., Sidiqi, M., Erasmus, P., Coleman, P.G., 2003. Anthroponotic cutaneous leishmaniasis, Kabul, Afghanistan. Emerg. Infect. Dis. 9, 727.

Reithinger, R., Mohsen, M., Leslie, T., 2010. Risk factors for anthroponotic cutaneous leishmaniasis at the household level in Kabul, Afghanistan. PLoS Negl. Trop. Dis. 4, e639.

Reyburn, H., Rowland, M., Mohsen, M., Khan, B., Davies, C., 2003. The prolonged epidemic of anthroponotic cutaneous leishmaniasis in Kabul, Afghanistan: 'bringing down the neighbourhood'. Trans. R. Soc. Trop. Med. Hyg. 97, 170-176.

Salah, A.B., Kamarianakis, Y., Chlif, S., Alaya, N.B., Prastacos, P., 2007. Zoonotic cutaneous leishmaniasis in central Tunisia: spatio-temporal dynamics. Int. J. Epidemiol. 36, 991-1000.

Stewart, C.C.. Brieger, W.R., 2009. Community views on cutaneous leishmaniasis in istalif, Afghanistan: implications for treatment and prevention. Int. Q. Community Health Educ. 29, 123-142.

Talmoudi, K., Bellali, H., Ben-Alaya, N., Saez, M., Malouche, D., Chahed, M.K., 2017. Modeling zoonotic cutaneous leishmaniasis incidence in central Tunisia from 2009-2015: forecasting models using climate variables as predictors. PLoS Negl. Trop. Dis. 11, e0005844.

Toumi, A., Chlif, S., Bettaieb, J., Alaya, N.B., Boukthir, A., Ahmadi, Z.E., et al., 2012. Temporal dynamics and impact of climate factors on the incidence of zoonotic cutaneous leishmaniasis in central Tunisia. PLoS Negl. Trop. Dis. 6, e1633.

World Health Organization, 2010. Report of a meeting of the WHO Expert Committee on the Control of Leishmaniases, Geneva, Switzerland, 22-26 March 2010. WHO Technical Report Series pp. 0512-3054.

Wu, Y., Qiao, Z., Wang, N., Yu, H., Feng, Z., Li, X., et al., 2017. Describing interaction effect between lagged rainfalls on malaria: an epidemiological study in south-west China. Malar. J. 16, 53. 